\title{
The Successes and Challenges of Kenya's Mombasa-Nairobi Standard Gauge Railway Transport Operations: A Special Reference to the Users
}

\author{
Nancy Muthoni Githaiga ${ }^{1,2}$ \\ ${ }^{1}$ Huazhong University of Science and Technology, Wuhan, China \\ 2 Murang'a University of Technology, Murang'a, Kenya \\ Correspondence: Nancy Muthoni Githaiga, Murang’a University of Technology, Murang’a, Kenya.
}

Received: November 18, 2020

Accepted: December 23, 2020

Online Published: March 2, 2021

doi:10.5430/rwe.v12n2p258

URL: https://doi.org/10.5430/rwe.v12n2p258

\begin{abstract}
This article examined the successes and challenges of Kenya's standard gauge railway for users in transport operations. The constrained operations in Kenya's existing colonial railway system have contributed to connectivity barriers and inefficiencies in the transport sector. Standard Gauge Railway's construction aimed to address these gaps and facilitate cargo and passenger transport operations in Kenya and across borders. This study used a descriptive research design in the form of a survey and adopted a mixed research method of qualitative and quantitative data with primary data collected through questionnaires and interviews. The population of interest was the train users (passengers and cargo transporters). The findings suggested that the railway has generally enhanced transport operations for passengers and freight through reduced travelling time, improved transport safety and security, and improved mobility and accessibility. While the SGR has led to reduced travel costs for passengers, the cost of freight transport remains relatively high.

The SGR has provided an alternative for freight and passenger transport, but there are challenges such as logistical and administrative challenges in cargo clearance, ticketing issues, and passengers' "First mile and Last mile" challenges. While the improvement of physical transport infrastructure and connectivity is significant, these challenges should be transformed into enablers to realize the railway's full potential. This research, therefore, recommends for; effective transfer of the cargo clearance and forwarding paperwork from Mombasa to Nairobi; development of a transport link between the railway and the two major cities to solve the "first mile" and "last mile" transport challenges for passengers, and to audit the ticketing system to identify and sanction cartels involved in ticketing malpractices. The overall conclusion is that generally, the railway has added value in Kenya's transport sector; passengers now have a cheaper, reliable and safer mode of transport while cargo is transported in a more reliable and safer way. The SGR is thus a transformative infrastructural project for Kenya; it symbolizes a country on a pressing need to transform herself into a middle-income economy supported by modern infrastructure.
\end{abstract}

Keywords: Kenya, Standard Gauge Railway (SGR), successes, challenges, transport operations, users

\section{Introduction}

The Kenya Standard Gauge Railway (SGR) was constructed to connect Kenyan cities and link the country to the neighbors, like Uganda and beyond. However, this article focuses on Kenya's Mombasa-Nairobi phase, which is complete and functional. Phase 2 of Nairobi to Naivasha is underway while the third phase was also tendered. Thus, the Mombasa-Nairobi Standard Gauge Railway connects Mombasa's vast Indian Ocean city with Nairobi, the country's capital and largest city (Githaiga \& Bing, 2019). This SGR runs parallel to the narrow-gauge KenyaUganda Railway, completed under British colonial rule in 1901. Its operator is Kenya Railways Corporation, and its Line length is 3,800 km (2,400 mi). SGR is part of Kenya's Vision 2030, the country's development program from 2008 to 2030 whose objective is to transform Kenya into a "newly industrialized, middle-income country providing all its citizens with a high quality of life in a clean and secure environment by 2030" (Ministry of State for Planning, 2008).

While this article concerns Kenya's Standard Gauge Railway transport operations, a recent phenomenon, Kenya's rail transport system dates back to colonial times. Railways were particularly favored because they facilitated the penetration of remote areas and proved incredibly efficient and economically beneficial to the colonial project (Njoh, 
2012). Until recently, Kenya was fully served by the Mombasa-Uganda rail system, developed by the colonial government in the early 1890s. However, over the years, the rail system has dilapidated due to technological and maintenance challenges becoming almost obsolete (Githaiga, Burimaso, Bing, \& Ahmed, 2019; Mairura, 2010; Mustapha \& Greenhill, 2017). As a result, roads have been used as the primary mode of transport in Kenya.

However, road transport has had significant problems, especially in urban areas and cities, such as traffic congestion and increased death rates. In a study carried out in Nairobi, the traffic forecast showed that the number of cars that have access to the city every day in 2007 was more than 330,000, which is why it is necessary to reconsider the revitalization of the railway as an alternative means of transport (Committee, 2018). Furthermore, the United Nations considers the rail mode of transport to be the most efficient and efficient in the movement of bulk freight over long distances on land in Africa and the movement of container traffic between cities and capitals. In Africa, however, only one percent of the world's rail passengers and only two percent of goods are transported by rail due to low connectivity on the continent (United Nations, 2009).

Therefore, the research set out to examine the successes and challenges of this new standard gauge railway on transport operations compared to the still existing colonial railway system's performance in Kenya. The article focused on the users' experiences and sought ways to address the old hurdles to meet the current challenges. The Chinese funded SGR has often been lauded as a great success in improving transport operations in Kenya. However, very few researchers have ventured to provide empirical evidence for this claim. Most of the current research and narratives on the Mombasa-Nairobi SGR impacts are limited in scope and polarized on the project's economic viability, debt rise, and self-sufficiency. Besides, little is known about the socio-economic impacts of this type of infrastructure (SGR) given that it is a bit recent in Africa, and the aim of the study is to fill this knowledge gap. For instance, Voskamp (2017) research entitled 'Investing in Transport Infrastructure in Developing Countries' was done before the completion of the SGR and heavily relied on secondary data (Voskamp, 2017). In their research entitled "Influence of Technology Strategies on the Performance of Standard Gauge Railways in Kenya," Jincheng focused on the technological aspect of the project (Jincheng, 2018) while (Githaiga \& Bing, 2019) focused on the overall socio-economic impact of the SGR using secondary data.

Therefore, this study sought to examine three main objectives; the SGR contribution to improving transports operations for users, the main challenges/concerns faced by SGR users, and the recommendations in improving the SGR operations. Understanding the successes and challenges of the SGR in Kenya's transport operations provides vital lessons for future infrastructure investment planning for Kenya and other African countries in general.

\section{Literature Review}

This section focused on the literature on three specific themes covered under transport operations, i.e., travel time and cost, safety and security, and mobility and accessibility. Travel time and cost savings are essential factors in passenger transportation's social and economic performance (Lingaitis \& Sinkevičius, 2014). Transport infrastructure improvements are linked to consistent and organized traffic timetables, rail traffic acceleration, and traffic information distribution. This minimizes travel and freight transportation time (Affuso, Masson, \& Newbery, 2003; Ajayi, 2005; Givoni, 2006). Research reveals that commuting times for passengers are significantly shorter in areas along the rail line than in those without the rail line. This is due to the faster speed of rail travel than other modes of transport, such as cars in comparable circumstances (Baum-Snow \& Kahn, 2005). Railway transport has been argued to provide the most cost-effective option for transporting people and non-time-sensitive freight over longer distances in Sub-Saharan Africa(Havenga, Simpson, \& Bod, 2014) as seen from the Ethiopia-Djibouti Railway (Quarters, 2018), Ghana railway (Jedwab, Kerby, \& Moradi, 2017) and Kenya-Uganda railway (Kerby, Moradi, \& Jedwab, 2018; Rodney, 1982). Modern transport and freight delivery networks globally need efficient, prompt, and cost-effective services; goods should be shipped from origin to destination at the lowest possible cost (Ubogu, 2011). These positive results directly boost economic growth in these regions due to improved market attraction; time and cost savings are the prerequisites for fostering business competitiveness for business consumers and a direct economic gain (Regional Development, 2014). Generally, transporting freight on railways is less costly than on roads since cargo transport on roads leads to high costs in vehicle operations, maintenance, and repair on roads and their users. If the situation persists, it will likely result in increased in-vehicle vibrations, resulting in cargo damage. In addition, the depreciation of road quality leads to an increase in road freight tariffs, which translates into an increase in commodity prices (Research, 2013). Railway transports large volumes of cargo, which leads to removal of the same from the roads leading to a reduction in road damage and carbon emissions. Therefore, railway transport has been hailed as the best transportation mode for bulky goods due to its greater regularity, capacity, and energy efficiency than other modes (AFrica Development Bank 2015). 
Studies on the safety and security effects of rail transport indicate that it is important to reduce traffic accident rates since traffic accidents impart social and economic costs to communities globally (Retallack \& Ostendorf, 2019). Although traffic congestion is considered less dangerous than drunk driving, it is significant in causing car accidents. The increased number of drivers, coupled with fewer roads, leads to congestion due to more drivers sharing less space. This road congestion, coupled with unsafe driving, could lead to a significant increase in car accidents. Studies have shown that rail transport is linked to fewer road accidents than other alternative modes of transport and, therefore, to a safer transport mode (Arndt et al., 2009). As the rail mileage expands in a city, truck congestion and motorist costs decrease (Winston \& Langer, 2004). For example, based on travel estimates for 2065, the Hume Region of Australia estimated a reduction of $\$ 12.6$ million per year in road accidents due to railway developments (Regional Development, 2014). Using the Federal Transit Administration (FTA) accident data, (Litman, 2006) indicated that as annual per capita transit passenger-miles increased in the US, fatality rates decreased. Besides, rail transport can lead to a significant reduction in road casualties and related costs. According to the African Development Bank (2015), the rail accident value is 50 times lower than that of the roads (AFrica Development Bank 2015). The rail schedule's fixed nature has been shown to increase pedestrian and passenger safety due to its predictable travel path and high visibility (Feigenbaum, 2013; Litman, 2019). This implies that rail systems reduce congestion and its associated costs; incremental rise in rail service leads to about eight times more shifts to travel for commute reasons than the same gradual increase in bus service (Litman, 2019). However, in another school of thought, some studies have criticized rail transit investments, arguing that they are not cost-effective in reducing traffic congestion. Investments in public transit are unlikely to significantly and meaningfully reduce congestion(Taylor, 2004). Therefore, despite the rail transport existence, the congestion levels are likely to keep increasing into the future due to an increase in population and a gradual increase in real wealth and preference changes (Stopher, 2004). Generally, however, rail transport is critical in reducing traffic congestion on the roads and reducing accidents, thus enhancing transport safety.

Finally, mobility is considered one of the essential characteristics of human activities since it helps to meet the basic need of moving from one location to another for commodities and travelers. Mobility enhances cultural, social, economic, and political activities regardless of their goal. Regions with better mobility have a better chance of developing than those with limited mobility. Therefore, it is one of the development indicators; better mobility is a driving force for development, while limited mobility hinders development (Feigenbaum, 2013). Mobility provision is a sector that provides services to its clients, creates employment as well as providing revenue from taxes, among others. Railway transport can provide a solution to accessibility by creating a better alternative to other modes of transport or a new economic corridor with high inter-regional accessibility. The primary assumption is that regions and cities linked to rail transport are transformed into extended functional areas by substantially increasing the travel intensity resulting in increased economic growth and development as a result of stimulation and market expansion in the region (Blum, Haynes, \& Karlsson, 1997). Improving the accessibility and connectivity of the various regions using trains makes it easier to travel, attracts more people to use rail transport (mobility), and thus makes rail transport more economically viable (Banister \& Berechman, 2001; Blanquart \& Koning, 2017; Guirao \& Soler, 2008; Shin, 2005). Investment in rail transport infrastructure improves accessibility, which, as a result, contributes to the potential growth of economic activity, which is mainly due to job creation and increased productivity (Banister \& Berechman, 2001; Guirao \& Soler, 2008; Hadas \& Ceder, 2010). Different regions' connectivity affects their competitiveness; regions compete for people's attraction, settlement, and business investors (Mishra, Welch, \& Jha, 2012). In today's global markets, industries need to have strong ties to compete effectively internationally. The extent of global connectivity could have an impact on investment decisions for local and international industries. Generally, people and investors are more likely to settle in areas with better rail links. As a result of better links attracting businesses and relocations, there may be agglomeration impacts, leading to higher productivity in the regions concerned.

\section{Theoretical and Conceptual Framework}

\subsection{Modernization Theory}

This study was guided by the modernization theory. The modernization theory began in the 1950s to explain how Western Europe and North American societies developed (Hussain \& Tribe, 1981; Lenin, 1964). The theory posits that communication and transportation become progressively sophisticated and accessible through the modernization process as society becomes more mobile and urbanized. Modernism has often been used to justify the implementation of certain types of structures and processes in underdeveloped regions in comparison with western civilizations, which are considered to possess unmatched democratic stability and economic prosperity; achieved 
through advancement in science and transport, technological progress and rationality, mobility and economic well-being (Tipps, 1973).

Theoretically, the relationship between transport infrastructure and modern development appears to be evident in developing countries. In Africa, the colonial and pre-colonial powers seemed to be aware of transport and modern development relations and heavily invested in transport infrastructure. Transport infrastructure provides a modern connectivity condition essential to the movement of people and commodities, particularly in a developing space economy (Herbst, 2000). Modern economies are after means of transport that increase the mobility of people and the movement of goods at the lowest possible cost, in addition to safer conditions and maximum environmental protection. As a result, rail has been given priority as an alternative means of transport for the reasons set out above. By applying the modernization theory, the researcher explores the SGR contribution to the transformation and modernization of Kenya's transport operations for users. Improved user transport operations, increased accessibility and mobility of people, enhanced service sector, and economic growth are part of a modernized society.

\subsection{Conceptual Framework}

Generally, investment in rail transport in most developing countries has not been a priority, as shown in the available literature. Besides, the existing railways have not been assessed in terms of their successes and challenges to transport operations for the respective countries' users. Therefore, every investment model for rail transport must account for the construction of the project and the impact of the transport operations that come with it. The author has drawn up a conceptual framework in Figure 1 to illustrate the link between the investment in the standard gauge rail and its transport operations benefits. The framework sets out the broad relationship between the variables of specific transport operations covered by this research; time travel and costs, safety and security, mobility, and accessibility. These relationships underscore a recurring theme in the literature that investment in rail transport can have multiple overlapping effects on user transport operations. Data on the relationship between rail transport and rail transport benefits are challenging to obtain in most developing countries.

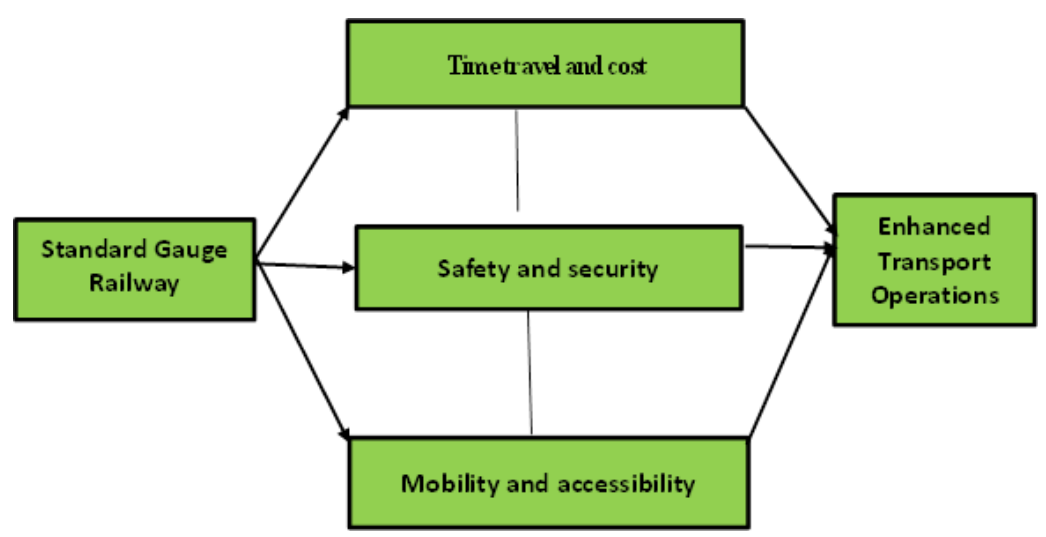

Figure 1. Conceptual framework of the impacts of SGR on transport operations

\section{Methodology}

This study used a descriptive research design in the form of a survey and adopted a mixed research method consisting of qualitative and quantitative data. Survey research designs are procedures for quantitative research in which investigators administer a survey to a sample or to the entire population of individuals to describe attitudes, opinions, behaviors, or characteristics (Mathiyazhagan \& Nandan, 2010). The researcher sought to collect data on the views of Kenya's SGR train users on its operations successes and challenges. The survey design was the most appropriate method by which the researcher could obtain opinions, attitudes, and suggestions on this subject. It also provided an appropriate tool for collecting a large amount of data, a practical framework for managing a large sample of groups, and robust data reliability as opposed to other designs. Data from both primary and secondary sources were used in this research. The primary sources included observations, questionnaires, and interviews, while the secondary sources included a review of the relevant literature from relevant journals, books, government documents, and other necessary documents. Besides, this research used quantitative and qualitative data; quantitative 
data was collected through questionnaires and analyzed through SPSS, while qualitative data was collected through interviews, observation, and analysis of documents.

Given that the main objective was to explore the successes and challenges of the Standard Gauge Railway in Kenya's Transport operations, ordinary train users were the most appropriate target population. They have had first-hand experience with the SGR. The train users include passengers and freight forwarders. The researcher focused on Nairobi and Mombasa for freight forwarders. The researcher decided on this population since they have a better chance of providing credible information based on their SGR services experience.

For the sample size and sampling procedures, the train has a capacity of 1,260 passengers, which formed the target population of passenger train users. This research used Yamane's (1967) sampling formula $\mathrm{n}=\mathrm{N} /\left(1+\mathrm{Ne}^{2)}\right.$ for the sample size determination as posited in (Yamane, 1967) where $\mathrm{n}$ is the sample size, $\mathrm{N}$ is the population size, and 'e' is the marginal error, for example at $95 \%$ level of confidence. From the formula, the sample size for ordinary train users was calculated as follows:

$$
\text { Sample size for passengers }=1260 /\left(1+1260\left(0.05^{2}\right)\right)=303
$$

The sample size of the passengers was, therefore, 303 passengers. Simple random sampling was used to select the train survey respondents. In this method, each member of the sample population has a known and equal chance of being selected (Kothari, 2004). Twelve freight forwarders were sampled for interviews, both from Nairobi and Mombasa, for representation purposes, as these are the two main hubs for freight transport. Purposeful sampling was used to select freight forwarders for interviews. Purpose sampling is argued to be appropriate when sampling for proportionality is not critical (Trochim, Donnelly, \& Arora, 2015). Before filling out the questionnaires or being interviewed, the respondents gave their oral consent. The data collected was analyzed using SPSS software, descriptive statistics. The findings were presented in the form of reports, tables, and figures. The data collected was checked for any errors that were corrected at the data analysis stage prior to the actual data analysis. Quantitative data from the questionnaire were encoded and entered on the computer for the computation of descriptive statistics. Descriptive analysis was carried out, which, as (Kothari, 2004) suggests, is an analysis of distributions of one variable, which provides profiles of groups, individuals, and other subjects on any of the multiple characteristics, such as size, frequency, preferences, and efficiency. The Statistical Package for Social Sciences (SPSS) was used to run descriptive analyses to generate frequency distribution and percentages. Tables and graphs were used to summarize the data while qualitative data from interviews were categorized into research objectives and reported in narrative form and quantitative presentation. Qualitative data was used to reinforce quantitative data.

\section{Results \& Discussion}

\subsection{Response Rate and Demographic Information}

Out of the 303 questionnaires distributed to SGR passenger users, 289 were found complete and valid for analysis representing a $95 \%$ response rate. All the twelve cargo transporters were interviewed; eight males and four females. The average response rate for all the respondents was found to be $95.6 \%$. The high response rate indicated that the data collected was sufficient to carry out the study (Field, 2005). The questionnaire respondents in this research were determined through simple random sampling. Considering that all population members had an equal chance of being selected, the data collected was unbiased. The quantitative results presented here include those collected from the respondents using questionnaires, while qualitative results were obtained from interviews and questionnaire open-ended questions.

As Table 1 shows, there were no significant gender issues for SGR use as there was a small gender disparity in the rate of turnout; male respondents were $58.1 \%$, while $49.1 \%$ were female. On age, there was a disproportionately large number of young people using the SGR, particularly in the age group between 18-30 and 30-40 years of age, at $50.9 \%$ and $38.8 \%$ respectively, representing $89.7 \%$ of the total passenger respondents. $41-50$ years and over 51 years averaged $8.7 \%$ and $1.7 \%$, respectively. The majority of travelers used the SGR for 2-5 times at 58\%, while those who used it for more than 5 times followed at $29 \%$, and the least were those who used it once at $13 \%$.

Table 1. Respondents' demographic information

\begin{tabular}{llll}
\hline VARIABLE & DEMOGRAPHIC & FREQUENCY & PERCENTAGE \\
\hline GENDER & Male & 168 & 58.1 \\
\hline & Female & 121 & 41.9 \\
\hline
\end{tabular}




\begin{tabular}{llll}
\hline EDUCATION LEVEL & & & \\
\hline & Primary Or Less & 2 & 0.7 \\
\hline & High School & 36 & 12.5 \\
\hline Diploma & 98 & 33.9 \\
\hline & Bachelor Degree & 118 & 40.8 \\
& Master Degree & 32 & 11.1 \\
\hline Doctorate & 3 & 1 \\
\hline AGE & & & 50.9 \\
\hline & $18-30$ & 147 & 38.8 \\
\hline & $31-40$ & 112 & 8.7 \\
\hline NUMBER OF TIMES USING SGR & Once & 25 & 1.7 \\
\hline & 2-5 Times & 168 & 12.8 \\
\hline & More Than 5 Times & 84 & 58.1 \\
\hline
\end{tabular}

Figure 2 shows that the most potent factor influencing the travelers' choice of the train as opposed to other means was speed/time at $86.3 \%$. Safety was the second most potent factor at $83.2 \%$. Punctuality was the third factor as to why travelers chose the SGR to travel at $60.6 \%$. Reliability followed closely at $58.1 \%$. Reduced traffic came in as the fifth reason at $49.8 \%$. The cost of travel using the SGR was not a significant factor as the results indicated that only $36.3 \%$ chose it as a reason for their choice of SGR use. 'Other reasons' came in as the last factor at $5.2 \%$.

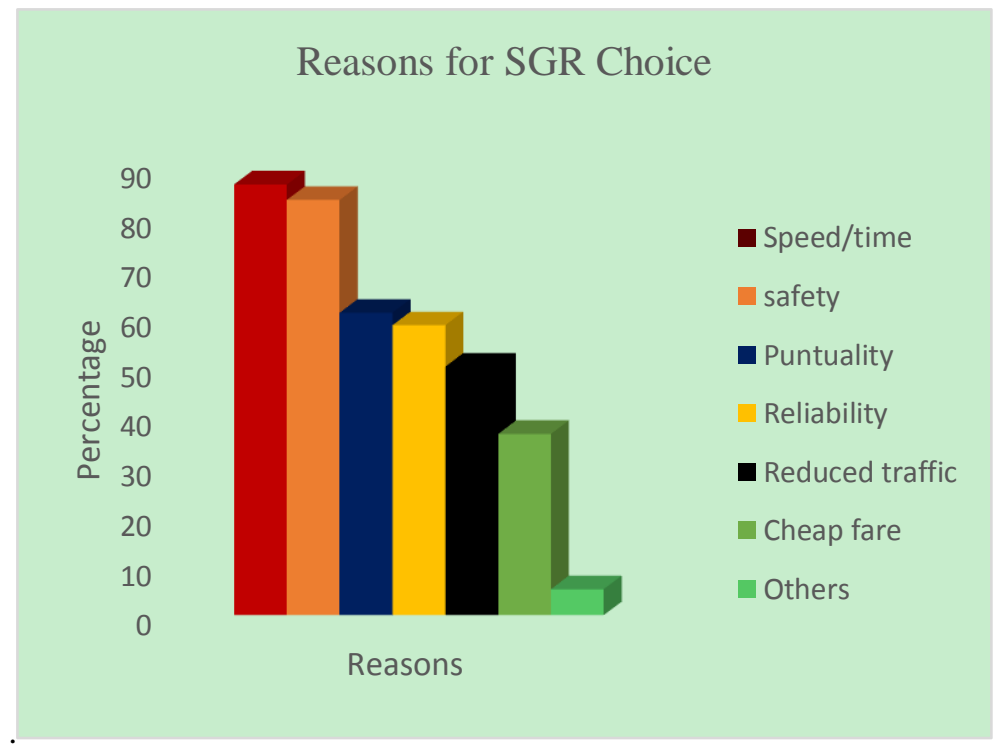

Figure 2. Reasons for choosing SGR

\subsection{Descriptive Statistics for Transport Operations}

The variables under transport operations are represented in three classifications; travel time and cost, safety and security, mobility, and accessibility, as shown in table 2 . The majority of the items had a strong impact since the 
mean was far below 2.5 on a five-point Likert scale. Additionally, most of the items displayed a small deviation from the mean, indicating that the data was homogeneous.

Table 2. Descriptive statistics for the individual construct variables under transport operations

\begin{tabular}{|c|c|c|c|c|c|}
\hline Variable & $\mathrm{N}$ & Minimum & Maximum & Mean & Std. Deviation \\
\hline \multicolumn{6}{|l|}{ Time and Cost } \\
\hline SGR faster to travel than road & 289 & 1 & 5 & 1.74 & .734 \\
\hline SGR cheaper to travel & 289 & 1 & 5 & 1.96 & .920 \\
\hline Sgr faster in goods transport & 289 & 1 & 5 & 1.79 & .679 \\
\hline $\begin{array}{l}\text { SGR increased the transport ca } \\
\text { services }\end{array}$ & 289 & 1 & 5 & 1.86 & .792 \\
\hline
\end{tabular}

\section{Safety and Security}

\begin{tabular}{llllll}
\hline Traffic Congestion reduction & 289 & 1 & 5 & 1.70 & .683 \\
\hline Reduced accidents on Msa/Nrb Highway & 289 & 1 & 5 & 1.88 & .725 \\
\hline Minimal Train accidents & 289 & 1 & 5 & 1.81 & .863 \\
\hline $\begin{array}{l}\text { SGR safer compared to road } \\
\text { Increased transport safety due to transporting goods } 289\end{array}$ & 1 & 5 & 1.85 & .790 \\
$\begin{array}{l}\text { on SGR } \\
\text { Personal security guarantee during the trip }\end{array}$ & 289 & 1 & 5 & 2.06 & .919 \\
\hline Safety Equipment clearly labelled & 289 & 1 & 5 & 1.82 & .764 \\
\hline Safety signs clearly labelled & 289 & 1 & 5 & 1.80 & .777
\end{tabular}

\section{Mobility and Accessibility}

\begin{tabular}{|c|c|c|c|c|}
\hline Convenient to get to and from the station & 1 & 5 & 3.62 & 1.190 \\
\hline $\begin{array}{l}\text { SGR has generally enhanced mobility and289 } \\
\text { accessibility }\end{array}$ & 1 & 5 & 1.80 & .721 \\
\hline $\begin{array}{l}\text { Easier to access } \\
\text { Mombasa/Nairobi }\end{array}$ & 1 & 5 & 1.62 & .630 \\
\hline Available means of transport to and from the station 289 & 1 & 5 & 1.72 & .590 \\
\hline Number of train stations are enough & 1 & 5 & 3.52 & 1.216 \\
\hline Enough security at the stations & 1 & 5 & 1.73 & .748 \\
\hline
\end{tabular}

Table 3. Descriptive statistics for mean rate scores for the construct variables under transport operations

\begin{tabular}{llll}
\hline & $\mathrm{N}$ & Mean & Std. Deviation \\
\hline Time & 289 & 1.7647 & .51875 \\
\hline Cost & 289 & 1.96 & .920 \\
\hline Safety \&Security & 289 & 1.8331 & .42026 \\
\hline Mobility\& Accessibility & 289 & 1.7751 & .54448 \\
\hline Valid N (listwise) & 289 & & \\
\hline
\end{tabular}




\subsubsection{Cost and Time}

Quantitative results indicated that most passengers agreed that SGR is a cheaper means to travel than other modes of transport with an aggregate mean of 1.96 and a faster means of travel than road transport with an aggregate mean of 1.76. Qualitative data from the interviews indicated that $90 \%$ of freight forwarders noted that the total cost of transporting freight to SGR was relatively higher than that of Mombasa Road to Nairobi Inland Container Deportation (ICD). They noted that the additional charges, once the goods arrive at the ICD, make it more expensive to transport cargo using the SGR than to transport it by road. They cited costs such as storage costs by the Kenya Ports Authority, last-mile transport costs from the ICD to the consignee's destination, cancellation charges due to delays in the return of empty containers to Mombasa, as well as costs for the return of empty containers from Nairobi to Mombasa. Besides, $87 \%$ of the sampled freight forwarders agreed that all factors held constant; transporting goods using the SGR from Mombasa to the ICD in Nairobi is significantly faster than the truck system, taking only approximately 6-8 hours.

The SGR has led to travel cost reduction and the fare is relatively affordable compared to other means like air and roads. The Madaraka Express fare for the passenger service economy class is 10 US dollars, which is cheaper than the public bus fare (14-20 US dollars). Children under three years travel free of charge, while those between three and 11 years old pay half the fare for both the first and the economy class. Those over 11 years of age pay full fare. Overall, these findings are per the findings from Australia where cost was quantified and revealed that railway led to reduced travel costs (Regional Development, 2014) as well as the colonial Kenya-Uganda railway, which cut transport costs by $90-95 \%$ (Kerby et al., 2018; Rodney, 1982). Generally, the railway has added value in Kenya's public transport and made the sector competitive to the advantage of the passengers in terms of cost; there is diversification in the transport sector providing passengers with a cheaper mode of transport in the SGR.

However, the total cost of transporting freight was found to be expensive and even higher than that of road transport. This was mainly due to additional charges once the cargo arrived at the ICD and the last mile's cost. Previous research shows that rail transport still offers the most cost-effective solution for long-distance non-time-sensitive freight transport in sub-Saharan Africa (Havenga et al., 2014), but this is not the case with Kenya's SGR. This could be due to a variety of factors; a report by the 'Joint Technical Committee on the Improvement of Efficiency and Cost-Effectiveness of Transportation of Cargo Using SGR' shows that the current average total transport for 20ft and 40ft containers from Mombasa to Nairobi by road is US\$ 650 and US\$ 850 respectively compared to the rail transport which is US\$ 1,420 and US\$2,120 respectively. The difference between road and rail for $20 \mathrm{ft}$ and $40 \mathrm{ft}$ is US\$ 770 (118\% increases) and US\$ 1,270 (149\% increase). As outlined in the report, additional costs in SGR cargo transport are storage, re-marshalling, demurrage, shipping line margin cost of returning empty containers by rail, and Kenya Ports Authority (KPA) moving of empties to container depots. Removing the shipping line margins, the cost of empty return by rail, and KPA moving of empties to container depots, the cost of $20 \mathrm{ft}$ would significantly reduce to US\$ 780, and 40ft to US\$ 1,095/1,170 (Committee, 2018). Though previous research indicates additional costs incurred in a rail journey cannot be eliminated due to railway transport's nature (Vierth et al., 2008), there is a need to reduce standard tariffs for cargo to promote regular volumes via the SGR. Railway transport is expected to cut freight costs, and goods should be transported from the origin to the destination at a minimal cost.

The SGR was also found to be a faster means of travel and cargo transport than other modes like road transport. Passenger travel time from Mombasa to Nairobi was shortened by rail from more than ten hours to approximately five hours, while freight trains are completed in less than eight hours; the journey could take up to 48hours by road. One of the most critical indicators of passenger and freight transport's economic and social efficiency is the value of travel time and cost savings (Lingaitis \& Sinkevičius, 2014). Time and cost savings are prerequisites for promoting business productivity for business users and are a direct economic benefit. They also lead to household and welfare gains for non-business users, which indirectly impact the economy.

\subsubsection{Safety and Security}

On safety and security issues, quantitative data indicated that the majority of passengers were satisfied with an overall mean of 1.83. This was further demonstrated by individual means. For example, they agreed that the SGR was safer than road transport (mean=1.84) because the train experienced minimal accidents, if any (mean=1.81). In addition, they agreed that the SGR increased road safety due to rail freight transport (mean=1.85), leading to a reduction in accidents (mean=1.88) and congestion (mean=1.70) along the Mombasa-Nairobi highway. Also, qualitative data showed that all freight transporters interviewed noted that the SGR is significantly safer and more secure in transporting their cargo than road transport. Thus, the results generally suggested that the SGR is a safer and more secure means of transport than the road, both in passenger and goods transport. A similar conclusion was 
reached by (Litman, 2006; Winston \& Langer, 2004), indicating that as the rail's mileage expands in a city, truck congestion and motorist costs decrease, increasing road safety and security. Several studies have also shown that rail transport is associated with fewer road accidents than alternative modes of transport (Litman, 2006). In Kenya, the SGR has been very significant in reducing traffic congestion, accidents, and related costs along the Mombasa-Nairobi highway by reducing freight trucks and buses on the roads. Transportation of freight and people by rail has enhanced overall transport safety and security for goods and services.

Furthermore, there has not yet been a documented major accident of the train wagons on the SGR, further reinforcing the SGR's safety thesis. It has been argued that the cost of accidents is 50 times lower for rail than for road transport, according to the African Development Bank report (2015), and in the event of train accidents, the damage may not be as severe compared to other means of transport. Data from the US Federal Railroad Administration (FRA) for both passenger rail and rail freight from 1998 to 2007 show that train accidents resulted in a single death and 98 injuries, while road-rail grade-crossing accidents resulted in 45 fatalities and 172 injuries (Ortiz, Weatherford, Greenberg, \& Ecola, 2008). Transport of hazardous freight to the SGR could also improve transport safety, particularly on the roads. As far as safety in freight transport is concerned, the transport of hazardous materials (flammable liquids, gases, and corrosive materials) is critical, and research has confirmed the large-scale damage caused by accidental or deliberate release of hazardous substances. Rail is therefore preferred when it comes to transporting these, and it increases road safety and, in the event of an accident, effective emergency response can significantly reduce the scale of human consequences on the rail, unlike on roads (Ortiz et al., 2008). As a result, the rail sector is believed to experience minimal accidents, and most rail accidents do not result in significant direct damage to equipment, track, and infrastructure. Thousands of road accidents are reported every year in Kenya, along the Nairobi-Mombasa highway, the main route for trucks transporting freight from Mombasa to other parts of the country and the region. The African Development Bank (AfDB) estimates that road traffic accidents in developing countries could be as severe as AIDS deaths by 2030 (AFrica Development Bank 2015). Therefore, developing mass transit systems could reduce these costs by moving from road to rail, and the SGR has played a significant role in enhancing transport safety and security.

\subsubsection{Mobility and Accessibility}

The majority of the passenger respondents agreed that the SGR has generally enhanced mobility and accessibility with an aggregate mean of 1.77. This was further demonstrated by individual means. For instance, it is now easier to access more areas along the Mombasa/ Nairobi route than before (mean=1.62), the train is easily accessible (mean=1.78), and there are available means of transport to and from the stations (mean=1.72). However, the majority noted that it was not convenient to get to and from the main terminal (Mombasa and Nairobi terminals) (mean=3.62 and were not satisfied with the number of stations (mean=3.52).

The results suggest that the SGR has increased mobility and accessibility between Nairobi and Mombasa as it is now easier to access more areas along Mombasa/Nairobi than before. Overall, these findings are consistent with the research findings reported by (Shin, 2005) which argued that improving the accessibility and connectivity of the various regions using trains provides greater convenience for travel, attracts more people to use rail transport (mobility), and thus makes rail transport more economically viable. Irrespective of its objective, mobility enhances cultural, social, economic, and political activities. Regions with better mobility are more likely to develop than those with limited mobility; therefore, it is one of the indicators of development, improving the efficiency of labor interactions while reducing the cost of distribution due to the resulting competitive gains (Feigenbaum, 2013). SGR has created a better transport alternative, thus addressing accessibility challenges between Nairobi and Mombasa. It has also encouraged the creation of a new economic corridor with high inter-regional accessibility.

\subsection{Challenges and Concerns}

This was an open-ended question in the questionnaire where the respondents were supposed to note any concerns they had with the passenger services. At the same time, it was an interview question to the cargo transporters. As shown in figure 3, the most salient concerns for passengers were on ticketing at $86 \%$ and 'first mile and last-mile' mobility and accessibility challenges at $89 \%$, while for cargo transporters, it was the administrative and logistical challenges at the Nairobi ICD at $93 \%$ and the loss of income for cargo freighters and truck owners at $96 \%$. 


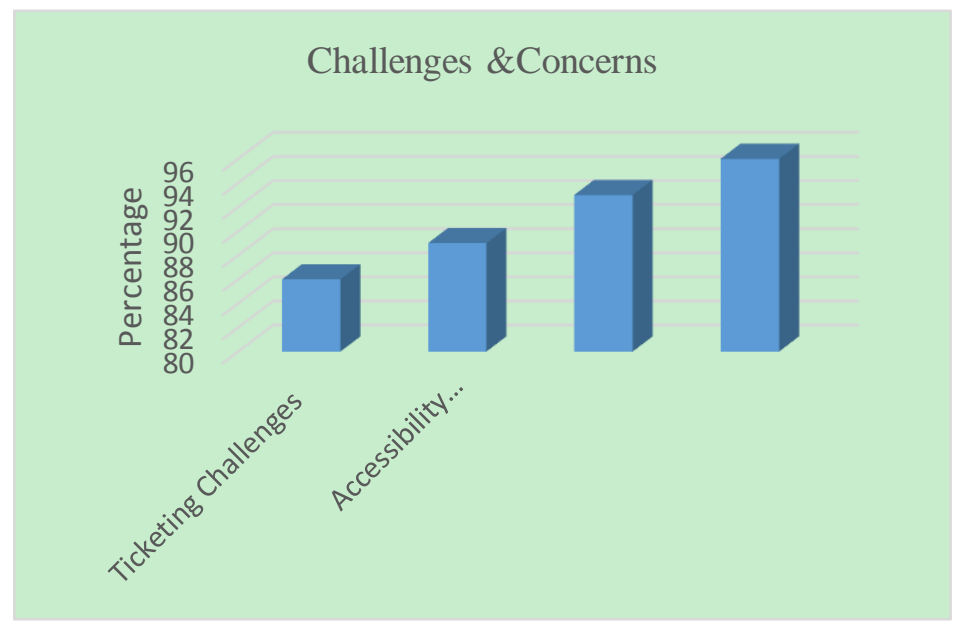

Figure 3. Challenges \& concerns

\subsubsection{Ticketing Challenges}

$86 \%$ of the passengers surveyed expressed dissatisfaction with the SGR's ticketing operations. Specifically, they cited inefficiencies in the online ticketing system, where it often indicates that tickets are sold in full, but they can purchase the same tickets through third parties (agents) at a higher price or through the counter at the train stations. The respondents noted that this was due to the hoarding of tickets by agents, the deliberate cancelation of last-minute tickets (by agents and individuals), and insider trading. Hoarding creates an artificial shortage of tickets, while agents' calculated last-minute cancellations affect ridership, leading to the train operating on a significant number of empty seats. At the same time, prospective customers are unable to access tickets.

An efficient ticketing system is a core in railway operations as it generally lowers costs, saves time on queuing, and increases operational efficiency (Zhao, Zhang, \& $\mathrm{Li}, 2019$ ). While it is reasonable to have empty seats due to various factors such as passengers being left by the train or actual cancellations, the respondents' concerns are serious and warrant investigation. Whereas bulk purchases are not illegal, hoarding and other related malpractices such as deliberate cancellations should not be allowed as the SGR is a public resource. The SGR was built on a loan and is expected to generate revenue for its self-sustainability, including the loan repayment (Githaiga \& Bing, 2019); this will not happen if it is not efficiently run. While Kenya Railways has made great strides by investing in e-ticketing technology, which has increased the efficiency and attractiveness of rail transport usage, more needs to be done to address the current concerns. There is a need to audit the ticketing system to identify cartels that engage in such malpractice and impose penalties on them. Furthermore, agents' issues should be seriously addressed and the cancelation policy reviewed for a more practical and financially sound one, e.g. more severe penalties, increased cancelation fees for agents, reduced access to bulk tickets, among others. If ticketing issues arise from the train's full capacity, operators should increase the number of trains per day to allow maximum SGR use, which will improve operations and generate more revenue.

\subsection{2 "First Mile" and "Last mile" Transport Challenges for Passengers}

$89 \%$ of the respondents indicated that access to Nairobi and Mombasa's central terminals is not convenient. The Mombasa and Nairobi terminals are located outside the cities, unlike the old train stations, and travelers need to use shuttles to access them. The Mombasa terminus is located in Miritini, which is out of town, and the shuttle from the old railway station to the terminus usually costs US\$2.5. At the same time, the CBD from Syokimau (Nairobi Terminal) to Nairobi costs US\$ as the researcher experienced." First mile" and "Last mile" Transport Challenges for Passengers not only increases the total cost of travel but also leads to a waste of time and other inconveniences. Previous research shows that improving the accessibility and connectivity of the various regions using trains makes it easier to travel, attracts more people to use rail transport (mobility), making rail transport more economically viable(Shin, 2005). There is a need for a readily available transport link between the two central railway stations and the central shopping/cultural area in these two major cities. An extension of passenger services termination to the old railway stations both in Nairobi and Mombasa is recommended. This will improve accessibility and aid in the restoration of Mombasa as an export city. 


\subsubsection{Logistical and Administrative Challenges for Cargo Transporters}

Logistical and administrative challenges at the Nairobi ICD were cited as severe setbacks in cargo transportation by 93\% of the interviewed cargo transporters. As outlined by the respondents, these challenges include a long clearance and verification process due to unstreamlined services from various independent government agencies, congestion due to insufficient storage at the yards, inadequate human resources, and a strained number of terminal tractors. These challenges cause unnecessary clearance delays that adversely affect the cargo's time and cost to the final destination. The freighters noted that it is challenging to clear goods within the stipulated four days, which leads to additional storage costs.

Independent reports confirm the goods clearance delays due to duplication of roles with KRA and KEBS requiring physical and manual re-inspection and verification of goods (Muchira, 2019). Seven container trains depart daily from Mombasa port to Nairobi, and the ICD yard population is sometimes up to 9,200 Twenty-Foot Equivalent Units (TEUs) compared to a yard capacity of 3,000 TEUs, which confirms the congestion challenges (Kazungu, 2018). These ICD inefficiencies increase the time and cost of cargo clearance and lead to severe business losses. It is estimated that losses of up to USD 100,000 are incurred daily (Kazungu, 2018). Previous research shows that in some developing countries, export and import administrative procedures alone prevent local producers from importing and exporting time-sensitive products (Blancas, Isbell, Isbell, Tan, \& Tao, 2013). For entrepreneurs in these countries, lengthy administrative procedures and inadequate logistics services are a significant disincentive to invest in quality and upgrade their products. As a result, firms are confined to the domestic market and import and export commodities with standard value-added products where customers are less demanding (Kumar, 2014).

Cargo clearance should be supported by legislation that defines the roles of each agency. Otherwise, the administrative and logistical challenges will remain. Addressing these inefficiencies at the ICD will have significant positive effects on improving the efficiency of freight transport. The SGR should improve freight and truck turnaround times by eliminating documentation and operational interruptions and delays, which will improve and smoothen the cargo clearance operation.

\subsubsection{Loss of Income for Freighters and Truck Owners}

Loss of revenue for freighters, truck owners, drivers, and loaders was also cited as a primary concern by $96 \%$ of the freight transporters interviewed. This is particularly the case in Mombasa, where the port is located, and other areas of the coastal province. These findings are consistent with the findings of previous research by (Kerby et al., 2018; Rodney, 1982), which showed that while colonial Kenya-Uganda rail transport lowered transport costs by $90-95 \%$, many people who earned their livelihood as porters were out of work as a result.

Several factors have led to this loss of income. First, the introduction of freight trains and the current Kenya Revenue Authority (KRA) and the Kenya Ports Authority (KPA) policies to shift operations of the Mombasa port to Nairobi have had detrimental effects on Mombasa city and its dwellers leading to the economic slowdown of the city. Presently, clearing of cargo is done at the ICD in Nairobi; Clearing and forwarding agencies in Mombasa, which employed many Kenyans, are now out of business. This has resulted in hundreds of businesses being shut down and hundreds of thousands of job losses in Mombasa and, more generally, the Coast Region for Container Freight Station (CFS) workers, drivers, and truck loaders. Second, the move by the Kenyan government in 2017 to have all cargo destined for local clearance transported through the SGR (Mutua, 2019) had significant adverse effects, with the trucks being the worst hit. This means that thousands of drivers and turn boys previously employed by these truck companies have been laid off. The go-downs and freight stations where the cargo was stored in anticipation of ferrying have also been shut down. Loss of income could lead to various harmful consequences on the social front, where families and SMEs could be forced to relocate in search of greener pastures. Some of these SMEs, like food retailers depended on truckers as their primary customers. Affected Mombasa residents will need to find alternative ways to earn a living. According to a report by the University of Nairobi, Mombasa county had a loss of Sh17.4 billion and 2,987 jobs equal to 8.4 per cent of annual revenue since the government ordered all freight destined for local clearance to be transported through the SGR (Ogolla, Rucha, Aroni, \& Ndua, 2019). Research shows that shifting from road to rail to freight transport leads to significant reallocation of transport, combined with job losses and the closure of freight access points and sidings (UNIFE, 2014). However, Kenya Railways should make arrangements that will allow former truck owners to become shareholders in freight forwarding. Where possible, truck owners should be empowered and allowed to purchase freight trains so that they are not entirely driven out of the transport business. This way, the SGR could make swift and profitable market entry by aiming to realize cargo owners' expectations and create win-win partnerships with clearing agents and road haulers. 


\section{Conclusion}

The aim of this research was to explore the successes and challenges of the SGR in transport operations for users in Kenya. The research also examined users' concerns and attempted to verify whether the available literature was consistent with what was observable on the ground. This is very important in filling the gap of the hitherto missing empirical research and contributing to the current discussions on the impact of the SGR on Kenya's transport operations, particularly from users' point of view. This is necessary because Kenya's colonial rail system has been constrained in many ways, leading to the systematic destruction of the road network, increased road accidents, and the loss of regional and international trade opportunities, among others. This pressure on existing infrastructure support has resulted in challenges for the country's transport sector and economic development in general.

The findings of this research show that the SGR has significantly improved transport operations for users in Kenya. In general, the SGR has enhanced passenger and freight transport operations through reduced travel time, improved transport safety and security, as well as improved mobility and accessibility. Although travel costs for passengers have been reduced, the cost of freight transport remains relatively high. The SGR has eased vehicle pressure on the country's road network since most freight is transported by rail, thus enhancing traffic and inter-relationship between the significant economic strongholds in Kenya. This means reduced congestion, reduced risk of road accidents and, most importantly, reduced road maintenance costs, mostly on the Mombasa-Nairobi highway, which has traditionally had serious traffic jams from trucks and other vehicles. Modern economies are after transport that enhances people's mobility and freight movement at the lowest possible cost, alongside safer conditions.

Improvement of physical transport infrastructure and connectivity is significant; however, current and potential challenges need to be addressed. Although the SGR has provided an alternative for freight and passenger transport between Mombasa and Nairobi, the high cost of transporting goods due to additional charges, logistical and administrative challenges for transporters, ticketing challenges and "First and Last Mile" accessibility challenges for passengers, need to be addressed. It should be noted that the cargo owners are interested in the lowest total cost of freight and the shortest turnaround time of the cargo. The Nairobi Internal Container Depot's logistical challenges need to be addressed by the relevant government agencies to realize the full potential of the SGR for freight transport. Transfer of cargo clearance and forwarding documents must be carried out effectively from Mombasa to Nairobi by integrating the Kenya Ports Authority's systems, the Kenya Revenue Authority and the SGR into effective and efficient real-time 24hours systems. Also, stakeholders should approximate global benchmarks in reducing the time from loaded trucks to ICD yards. Besides, security improvements could improve the productivity of the ICD for 24-hour operations. There is also a clear need for a readily available transport link between the railway and the two major cities to solve the "first mile" and "last mile" transport challenges for passengers. Also, an efficient ticketing system is a core in railway operations. Thus, there is a need to audit the system to identify the cartels that engage in ticketing malpractices and punitive sanctions taken against them. Besides, the government and relevant stakeholders could develop policies to ensure healthy competition and a sustainable environment for freight transport stakeholders and strategies to enhance sustainable employment opportunities. Such policies could include creating special economic zones and other potential industrial parks for a sustainable environment for all stakeholders. Strong industrial links and competitive industrial sectors are built up with efficient and reliable transport infrastructure.

Kenya's economic take-off cannot be achieved without the development of infrastructure. This includes modern technology and efficient means of transport for cargo and passengers such as the SGR. Further, freight and passenger transport are at the center of sustainable socio-economic development as it enhances economic growth, improves access and connects societies, promotes trade, and aids in poverty alleviation. Safe, secure, affordable, energy-efficient, reliable, environmentally friendly and regulated freight and passenger transport contribute to economically efficient, environmentally sound and socially equitable development. In conclusion, the SGR is a transformative infrastructure project for Kenya, symbolizing the country's urgent need to transform itself into a middle-income economy supported by modern infrastructure.

\section{References}

Affuso, L., Masson, J., \& Newbery, D. (2003). Comparing investments in new transport infrastructure, roads versus railways. Journal of Fiscal Studies, 24(3), 275-315.

AFrica Development Bank. (2015). Rail infrastructure in africa: financing policy options. Abidjan, Côte d'Ivoire: AFrica Development Bank: Transport, Urban Development \& ICT Department.

Ajayi, J. O. A. (2005). The effects of rail transport on socio-economic growth of Nigeria. Master Thesis. 
Arndt, J. C., Morgan, C., Overman, J. H., Clower, T. L., Weinstein, B. L., \& Seman, M. (2009). Transportation, social and economic impacts of light and commuter rail. Technical Report, Texas Transportation Institute, Report 0-5652-1.

Banister, D., \& Berechman, J. (2001). Transport investment and the promotion of economic growth. Journal of Transport Geography, 9, 209-218.

Baum-Snow, N., \& Kahn, M. E. (2005). Effects of urban rail transit expansions: evidence from sixteen cities, 1970-2000. Brookings-Wharton Papers on Urban Affairs.

Blancas, L. C., Isbell, J., Isbell, M., Tan, H. J., \& Tao, W. (2013). Efficient logistics; a key to vietnam's competitiveness: the world bank.

Blanquart, C., \& Koning, M. (2017). The local economic impacts of high-speed railways: theories and facts. European Transport Research Review, 9(2). https://doi.org/10.1007/s12544-017-0233-0

Blum, U., Haynes, K. E., \& Karlsson, C. (1997). The regional and urban effects of high-speed trains. The Annals of Regional Science, 31, 1-20.

Committee, J. T. (2018). Report of the joint technical committee on the improvement of efficiency and cost effectiveness of transportation of cargo using SGR.

Feigenbaum, B. (2013). High-speed rail in europe and Asia: lessons for the united States. Policy Study 418.

Githaiga, N. M., \& Bing, W. (2019). Belt and road initiative in Africa: the impact of standard gauge railway in Kenya. China Report, 55(3), 219-240. https://doi.org/10.1177/0009445519853697

Githaiga, N. M., Burimaso, A., Bing, W., \& Ahmed, S. M. (2019). The belt and road initiative: opportunities and risks for Africa's connectivity. China Quarterly of International Strategic Studies, 5(1), 117-141.

Givoni, M. (2006). Development and impact of the modern high-speed train: a review. Transport Reviews Journal, 26(5), 593-611.

Guirao, B., \& Soler, F. (2008). Impacts of the new high speed rail services on small tourist cities: the case of Toledo (Spain). WIT Transactions on Ecology and the Environment, 117.

Hadas, Y., \& Ceder, A. (2010). Public Transit Network Connectivity. Journal of the Transportation Research Board.

Havenga, J. H., Simpson, Z. P., \& Bod, A. D. (2014). South Africa's freight. Journal of Transport and Supply Chain, $8(1)$.

Herbst, J. (2000). States and power in Africa: comparative lessons in authority and control. Princeton, NJ: Princeton University Press.

Hussain, A., \& Tribe, K. (1981). Marxism and the agrarian question, german social democracy and the peasantry, 1890-1907.

Jedwab, R., Kerby, E., \& Moradi, A. (2017). History, path dependence and development: evidence from colonial railroads, settlers and cities in Kenya. The Economic Journal, 127(603), 1467-1494.

Jincheng, L. (2018). Influence of technological strategies on performance of standard gauge railway in Kenya. Masters of Business Administration, University of Nairobi, University of Nairobi.

Kazungu, S. (2018). Nairobi ICD capacity overstretched, says Kifwa. Business Daily Africa. Retrieved from https:/www.businessdailyafrica.com/news/counties/Nairobi-ICD-capacity-overstretched/4003142-4755670-wp 2jum/index.html

Kerby, E., Moradi, A., \& Jedwab, R. (2018). 3 policy lessons from Africa's colonial railways. Retrieved from https://www.theigc.org/blog/what-policymakers-can-learn-from-africas-colonial-railways/

Kothari, C. R. (2004). Research methodology; methods and techniques. India: New Age International (P) Ltd, Publishers.

Kumar, A. (2014). Freight logistics and intermodal transport implications for competitiveness (Vol. 175). New Delhi: Institute for Studies in Industrial Development.

Lenin, V. I. (1964). The development of capitalism in russia; the process of the formation of a home market for large-scale industry. Progress Publishers. 
Lingaitis, V., \& Sinkevičius, G. (2014). Passenger Transport by Railway: Evaluation of Economic and Social Phenomenon. Procedia - Social and Behavioral Sciences, 110, 549-559. https://doi.org/1016/j.sbspro.2013.12.899

Litman, T. (2006). Comprehensive evaluation of rail transit benefits. Journal of Transport Policy.

Litman, T. (2019). Evaluating public transit benefits and costs; best practices guidebook. Victoria Transport Policy Institute: Victoria Transport Policy Institute.

Mairura, O. (2010). Nairobi - emerging metropolitan region: development planning and management opportunities and challenges. Nairobi Metropolitan Region: 46th ISOCARP Congress 2010.

Mathiyazhagan, T., \& Nandan, D. (2010). Survey research method. Media Mimansa.

Ministry of State for Planning, N. D. A. V. (2008, June). Launching of Kenya vision 2030 speech by his excellency hon. Mwai Kibaki, CGH, MP. Retrieved from https://planning.go.ke/?option=com_content\&view=article\&id=199\%3Alaunching-ofkenya-vision-2030-speech -by-his-excellency-hon-mwai-kibaki-cgh-mp\&catid=56\%3Aothers\&Itemid=96

Mishra, S., Welch, T. F., \& Jha, M. K. (2012). Performance indicators for public transit connectivity in multi-modal transportation networks, National Center for Smart Growth Research and Education. University of Maryland, United States University of Maryland.

Muchira, N. (2019). Kenya: Cargo pile-up in nairobi as agencies clamp down on tax evasion, fake goods. The East African. Retrieved from https://allafrica.com/stories/201906040718.html

Mustapha, S., \& Greenhill, R. (2017). An 'age of choice' for infrastructure financing? Evidence from Kenya. London: Overseas Development Institute.

Mutua, J. (2019). MPs summon Macharia over order on SGR cargo. Business Daily. Retrieved from https://www.businessdailyafrica.com/economy/MPs-summon-Macharia-over-order-on-SGR-cargo/3946234-53 57612-eejjw8z/index.html

Njoh, A. J. (2012). Impact of transportation infrastructure on development in east Africa and the Indian ocean region. Journal of Urban Planning and Development, 138(1), 1-9. https://doi.org/10.1061/(asce)up.1943-5444.0000091

Ogolla, K., Rucha, K., Aroni, J., \& Ndua, G. (2019). Report on the socio economic impact of the sgr on the port city of Mombasa. Nairobi: School of Business, University of Nairobi.

Ortiz, D. S., Weatherford, B. A., Greenberg, M. D., \& Ecola, L. (2008). Improving the safety and security of freight and passenger rail in pennsylvania: RAND Corporation.

Quarters, A. (2018). Ethiopia lauds economic impact of China-built Ethiopia-Djibouti railway. African Quarters.

Regional Development. (2014). High speed rail economic and social benefits for the hume region. Deloitte Access Economics Pty Ltd.

Research, C. F. S. A. I. (2013). 10th annual state of logistics survey for South Africa.

Retallack, A. E., \& Ostendorf, B. (2019). Current understanding of the effects of congestion on traffic accidents. International Journal of Environmental Research and Public Health, 16(18).

Rodney, W. (1982). How Europe underdeveloped Africa. Howard University Press.

Shin, D. (2005). Recent experience of and prospects for high-speed rail in Korea: implications of a transport system and regional development from a global perspective California HSR Series, Working paper 2005-02. Berkeley: University of California.

Stopher, P. R. (2004). Reducing road congestion, a reality check. Transport Policy, 11(2), 117-131.

Taylor, B. D. (2004). The politics of congestion mitigation. Journal of Transport Policy, 11(3), 299-302.

Tipps, D. C. (1973). Modernization theory and the comparative study of societies: a critical perspective. Comparative Studies in Society and History, 15(2), 199-226.

Trochim, W., Donnelly, J., \& Arora, K. (2015). Research methods: the essential knowledge base (2nd ed.). Boston: Nelson Education, Cengage Learning.

Ubogu, A. E. (2011). The potentials of rail-road integration for port-hinterland freight transport In Nigeria. International Journal for Traffic and Transport Engineering, 1(2), 89-107. 
UNIFE, T. E. R. I. (2014). Megatrucks versus rail freight?. Germany: The Voice of European Railways.

United Nations, U. (2009). The transport situation in africa: economic and social council, economic commission for Africa. Sixth Session of the Committee Trade Addis Ababa, Ethiopia.

Vierth, I., Berell, H., McDaniel, J., Haraldsson, M., Hammarström, U., Yahya, M.-R., ... Björketun, U. (2008). The effects of long and heavy trucks on the transport system. Sweden: Ministry of Enterprise, Energy and Communications.

Voskamp, R. (2017). Investing in Transport Infrastructure in Developing Countries. International Bachelor of Economics and Business Economics (IBEB); Urban, Port and Transport Economics, Eramus Universiteit, Rotterdam.

Winston, C., \& Langer, A. (2004). The effect of government highway spending on road users' congestion costs. Report, Federal Highway Administration.

Yamane, T. (1967). Statistics: an introductory analysis (2nd ed.). New York: Harper and Row.

Zhao, Y., Zhang, D., \& Li, J. (2019). Research on risk assessment technology of China's railway ticket selling and reservation system. Journal of Physics: Conference Series, 1325. https://doi.org/10.1088/1742-6596/1325/1/012006

\section{Copyrights}

Copyright for this article is retained by the author(s), with first publication rights granted to the journal.

This is an open-access article distributed under the terms and conditions of the Creative Commons Attribution license (http://creativecommons.org/licenses/by/4.0/). 